\title{
Patient Adherence to a Cardiovascular Rehabilitation Program: What Factors Are Involved?
}

\author{
María José Bustamante ${ }^{1}$, Giovanna Valentinoㄹ, Verónica Krämer ${ }^{1}$, Marcela Adasme ${ }^{1}$, \\ Dominique Guidi ${ }^{1}$, Camila Ibara ${ }^{1}$, Cinthia Casasbellas ${ }^{1}$, Lorena Orellana1, \\ Marcelo Fernández ${ }^{1}$, Carlos Navarrete ${ }^{2}$, Mónica Acevedo ${ }^{*}$ \\ ${ }^{1}$ División de Enfermedades Cardiovasculares, Facultad de Medicina, Escuela de Medicina, Pontificia \\ Universidad Católica, Santiago, Chile \\ ${ }^{2}$ Departamento de Matemáticas, Facultad de Ciencias, Universidad de La Serena, La Serena, Chile \\ Email: ${ }^{*}$ macevedo@med.puc.cl
}

Received 21 July 2015; accepted 4 September 2015; published 7 September 2015

Copyright (C 2015 by authors and Scientific Research Publishing Inc.

This work is licensed under the Creative Commons Attribution International License (CC BY). http://creativecommons.org/licenses/by/4.0/

\section{Open Access}

\section{Abstract}

Background: Phase II cardiac rehabilitation (CR) is a class IA indication in patients suffering a cardiovascular event (CV). Current guidelines suggest 36 exercise sessions over a period of 3 months. The main aim of this study was to analyze the rate of adherence to a cardiac rehabilitation program and the factors influencing it. Methods: This was a cross-sectional study in 421 secondary prevention patients, who assisted to a Phase-II-CR program between 2007 and 2014. At baseline and program end, patients completed a 6-minute walk test and the Short-Form 36 Health Survey (SF-36). Vital signs and anthropometric measurements were also collected. Adherence was quantified as the percentage of individuals who attended all 36 sessions of the program. Factors considered for affecting adherence included: cardiovascular risk factors (RFs), type of health insurance (public or private), aerobic capacity, and SF-36 score parameters. Results: Adherence to Phase-IICR was $33 \%$, with no significant differences between men and women. The regression model fully adjusted for age, sex, RFs, type of health insurance and SF-36 score, showed that a SF-36 score <50 on physical health (odds ratio (OR): 11.47; 3.99 - 32.99; $p<0.0001$ ) and smoking (OR: 4.41; 1.25 15.62; $p=0.02$ ) were strong predictors for non-adherence. A trend for better adherence was observed in subjects older than 50 years compared to those aged between 17 and 50 years $(37 \%$ versus $23 \%$, respectively; $p=0.05$ ). No significant differences were observed in adherence according to RFs clustering. Conclusions: Adherence to Phase-II-CR is low in our population. Patientrelated factors, such as SF-36 score and smoking, were the best determinants of Phase-II-CR adherence. Health system-related factors did not influence adherence in this population. Prospective

"Corresponding author.

How to cite this paper: Bustamante, M.J., et al. (2015) Patient Adherence to a Cardiovascular Rehabilitation Program: What Factors Are Involved? International Journal of Clinical Medicine, 6, 605-614. 
studies are warranted to determine all the factors which may influence adherence to Phase-II-CR programs.

\title{
Keywords
}

\author{
Cardiac Rehabilitation, Adherence, Secondary Prevention
}

\section{Introduction}

Cardiovascular disease (CVD) is the most common cause of death in Chile and is responsible for $27 \%$ of total deaths. Approximately 35\% of all CV deaths are due to acute myocardial infarction (MI) [1] and although the rate of MI mortality has remained steady in recent years, its incidence in the younger population has increased significantly [2]. Therefore, it is of utmost importance to promote lifestyle interventions in these patients. Cardiovascular rehabilitation (CR) programs are associated with a reduction in CVD morbidity and mortality as well as improvements in the control of cardiovascular risk factors (RFs), exercise tolerance, control of anxiety and stress, and quality of life, among others [3]-[6].

The latest guidelines from the American College of Cardiology (ACC), the American Heart Association and the European Society of Cardiology have positioned CR programs with an indication class I, level A in secondary prevention [7]. The completion of the 36 sessions (over approximately 3 months) of Phase-II-CR has been associated with a lower risk of death and MI at 4 years compared with those performing fewer sessions [8]. Recent studies have also demonstrated a dose-response relationship in CR (i.e., the greater the adherence to the program, the lower the CVD morbidity and mortality) [8] [9]. Despite these benefits, participation in CR programs remains low, with only $10 \%$ to $20 \%$ of patients who survive an MI entering a secondary prevention program [8] [10]. This percent is even lower in Latin America with a referral rate around 5\% [11]. Moreover, a significant percentage of these individuals leave the program within the first two weeks [12]. The reasons for poor adherence to and underutilization of CR appear to be multifactorial: the patient's age, income, distance from the health center, and personal beliefs of referring physicians about the benefits of Phase-II-CR are among some of the related factors [10] [12]-[14]. Patient specific factors, such as cardiovascular RFs and RF clustering, may also influence adherence to this treatment. Despite the importance of Phase-II-CR as part of the secondary prevention after a CVD event, it is not included as part of hospital discharge instructions for most patients in several countries in Latin America.

Finally, adherence to CR programs is critically important to get the maximum benefits of exercise and the improvement in functional capacity [5] [9]. Therefore, the main aim of this study was to describe adherence rates to a Phase-II-CR program in Chile and evaluate the factors that influence it.

\section{Materials and Methods}

The study used a cross-sectional design and included a sample of subjects who participated in a Phase-II-CR program between 2007 and 2014 in an ambulatory setting of a university hospital. Exclusion criteria included subjects who did not have any history of atherosclerotic cardiovascular disease. Therefore, the sample consisted of 421 men and women with definite history of coronary heart disease (CHD). Mean age was of $59 \pm 12$ years.

\subsection{Data Collection}

Data were collected on the admission to the Phase-II-CR program. All subjects were interviewed by the nurse in charge of the program to obtain demographic, medical cardiovascular RF history, and medication intake data. All the information was entered in a database specifically designed for the program. Upon admission, each subject underwent a graded symptom-limited exercise stress test on a treadmill. Total duration of exercise, metabolic equivalents (METs) and maximum blood pressure and heart rate were recorded. In addition, a 6-minute walk test (6MWT), anthropometric parameters, and the 36-item Short Form Health Survey (SF-36) were measured and collected at baseline and at the end of the 36 sessions. For the 6MWT, the total distance walked and vital signs were recorded. 
The following criteria were identified as conditions that could influence patient adherence to the Phase-II-CR program:

1) Hypertension: subjects with physician-stated diagnosis of hypertension, with or without drug treatment.

2) Dyslipidemia: subjects with physician-stated diagnosis of hypercholesterolemia, hypertriglyceridemia and/ or low HDL ( $<40$ or $<50 \mathrm{mg} / \mathrm{dL}$, in men and women respectively), with or without drug treatment.

3) Obesity: subjects with BMI $\geq 30 \mathrm{mg} / \mathrm{kg}^{2}$ and those with abdominal obesity $\geq 90 \mathrm{~cm}$ (men) and $\geq 80 \mathrm{~cm}$ (women) according to published criteria [15] [16].

4) Diabetes and insulin resistance: those with medical diagnosis, with or without medication.

5) Physical inactivity: classification of "sedentary leisure time" was used [17]. Sedentary subjects were defined as those who reported no sport or physical activity of at least 30 minutes, 3 times per week, outside of working hours during the last month. This method has previously shown a direct and significant correlation with maximal aerobic power measured in METs [18].

6) Smoking: categorized by self-report as follows: no smoking, daily smoking ( $\geq 1$ cigarette/day), current smoking (daily + occasional, $<1$ cigarette/day), or ex-smoker (last cigarette $>6$ months) [17].

7) Family history of CHD: present if a subject had a direct relative (male $<55$ years old or woman $<65$ years old) who suffered a cardiovascular event.

8) Type of health insurance: Private (ISAPRE) or Public (FONASA) health insurance.

9) Aerobic capacity: total METs achieved in the exercise stress.

10) Quality of life: emotional and Physical health score on SF-36 was used [19].

All subjects admitted to the program provided written informed consent approved by the local ethics committee, which authorized the use of data for academic purposes, protecting confidentiality.

\subsection{Adherence}

The concept of adherence was applied to the total group of subjects, and it was quantified as the percentage of subjects who attended all 36 sessions of the Phase-II-CR program.

\subsection{Short Form 36 (SF-36) Health Survey}

The SF-36 consists of 36 questions including domains of physical functioning, physical role, body pain, general health, vitality, social function, emotional role, and mental health. Scores are subdivided into two sub-scales corresponding to two components: physical and emotional health according to the standards of the US SF-36. [19]. This survey was conducted upon the admission of the patient to the Phase-II-CR program and after its completion (conclusion of the 36 sessions). Scores less than 50 for each component were used as cut-offs values of low quality of life.

\subsection{Clustering of Risk Factors}

Risk-factor clustering was presented as the cumulative number of RFs previously described in the condition's criteria detailed above (from 1 to 7 ). According to this clustering, subjects were classified into 3 groups: Group 1: 0 to 1 RF, Group 2: 2 to 4 RFs, and Group 3: >4 RFs.

\subsection{Statistical Analysis}

The results of the tables were expressed as mean (SD) or frequency (\%). Comparisons between sex were based on ANOVA and Fisher exact test. Comparisons among adherence SF-36 survey, and baseline functional capacity were determined using Student's t-test.

To analyze the existence of factors which positively or negatively affected adherence, a logistic regression model, adjusted for age, sex, RFs, type of health insurance, and score in the SF-36 health survey was used.

\section{Results}

A total of 421 subjects were included in this analysis: $18 \%$ were women; mean age of the group was $59 \pm 12$ years old. Table 1 displays demographic characteristics and risk factor prevalence of the total group according to adherence status (adherent versus non-adherent). The rate of adherence to the 36 sessions of Phase-II-CR 
Table 1. Demographic characteristics and risk factor prevalence of the total group according to adherence to the Phase II cardiac rehabilitation program.

\begin{tabular}{|c|c|c|c|c|}
\hline Characteristics & $\begin{array}{l}\text { Total Group } \\
(\mathrm{n}=421)\end{array}$ & $\begin{array}{l}\text { Adherent Group } \\
\qquad(\mathrm{n}=141)\end{array}$ & $\begin{array}{l}\text { Non-adherent Group } \\
\qquad(\mathrm{n}=280)\end{array}$ & $p$-value \\
\hline Female gender, \% & $18 \%$ & $16 \%$ & $19 \%$ & NS \\
\hline Age, years & $59 \pm 12$ & $60 \pm 12$ & $59 \pm 12$ & NS \\
\hline \multicolumn{5}{|l|}{ Risk Factors } \\
\hline Hypertension, \% & $56 \%$ & $52 \%$ & $58 \%$ & NS \\
\hline Diabetes, \% & $17 \%$ & $17 \%$ & $17 \%$ & NS \\
\hline Dyslipidemia, \% & $86 \%$ & $87 \%$ & $86 \%$ & NS \\
\hline Obesity, \% & $21 \%$ & $16 \%$ & $24 \%$ & 0.07 \\
\hline Smoking, \% & $7 \%$ & $2 \%$ & $9 \%$ & $<0.01$ \\
\hline Sedentary, \% & $74 \%$ & $67 \%$ & $78 \%$ & 0.03 \\
\hline \multicolumn{5}{|l|}{ Health care insurance system } \\
\hline Public health system, \% & $21 \%$ & $25 \%$ & $19 \%$ & NS \\
\hline Private health system, \% & $78 \%$ & $74 \%$ & $80 \%$ & NS \\
\hline No health insurance, \% & $1 \%$ & $1 \%$ & $1 \%$ & NS \\
\hline \multicolumn{5}{|l|}{ Intervention } \\
\hline Cardiac surgery, \% & $35 \%$ & $38 \%$ & $33 \%$ & NS \\
\hline Angioplasty, \% & $49 \%$ & $50 \%$ & $48 \%$ & NS \\
\hline Medical, \% & $16 \%$ & $13 \%$ & $19 \%$ & NS \\
\hline \multicolumn{5}{|l|}{ Educational Level } \\
\hline Primary or Secondary, \% & $15 \%$ & $11 \%$ & $16 \%$ & NS \\
\hline Technical, \% & $17 \%$ & $14 \%$ & $17 \%$ & NS \\
\hline University, \% & $69 \%$ & $75 \%$ & $67 \%$ & NS \\
\hline \multicolumn{5}{|l|}{ Quality of life survey (SF-36) } \\
\hline SF-36 on physical health score & $74 \pm 17$ & $81 \pm 12$ & $70 \pm 18$ & $<0.0001$ \\
\hline SF-36 on emotional health score & $68 \pm 22$ & $76 \pm 18$ & $64 \pm 21$ & $<0.0001$ \\
\hline
\end{tabular}

Data are mean \pm SD, except where indicated. T-tests were used to determine differences between the non-adherent and adherent group. *Adherence was defined as attendance at all 36 sessions of the phase II cardiac rehabilitation program. NS = not significant; SF-36 = Short Form 36 health survey.

program was 33\%. No significant differences were observed between men and women (35\% versus 29\%, respectively). Overall, RF prevalence was: dyslipidemia $86 \%$, hypertension $56 \%$, diabetes $17 \%$, obesity $21 \%$, smoking 7\%, insulin resistance 13\%, 74\% sedentary lifestyle, and 25\% family history of CHD. Thirty-five percent of patients had coronary artery bypass surgery, $49 \%$ percutaneous coronary revascularization, either balloon angioplasty or stenting, and $16 \%$ only received optimal medical treatment.

A significant difference was observed between the following conditions and adherence (i.e., "worse" adherence”): smoking ( $p<0.01)$, sedentary behavior prior to the Phase-II-CR program ( $p=0.03)$, and SF-36 score $<50$ in physical health $(p<0.0001)$.

As shown in Figure 1, a better rate of adherence was observed in patients older than 50 years old (37\% adherence rate compared with $23 \%$ in patients 17 to 50 years old; $p=0.05$ ). When the group was analyzed by smoking status, better adherence was demonstrated in non-smokers versus smokers: $35 \%$ versus $10 \%(p<0.01)$. 

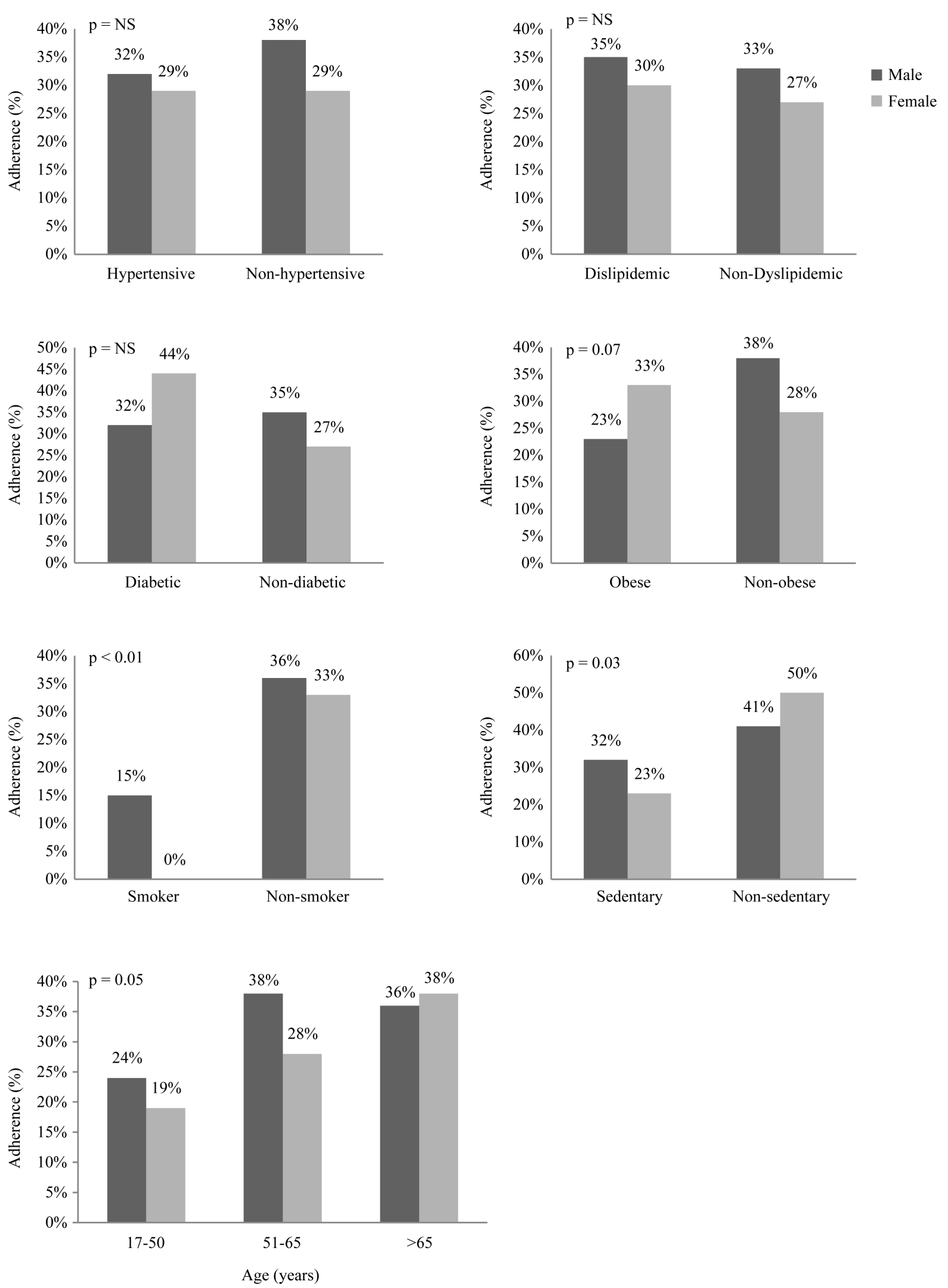

Figure 1. Rates of adherence by gender and cardiovascular risk factors. 
Likewise, a higher adherence was observed in the previously active versus previously sedentary subjects (42\% vs $30 \% ; p=0.03)$. The adherence rate was lower in previous sedentary women (23\%) than men (32\%). Moreover, a higher adherence rate was seen in non-obese compared to obese patients ( $36 \%$ vs $25 \%$, respectively), however it did not reach statistical significance $(p=0.07)$.

When analyzing the adherence according to the clustering of RF, no significant differences were observed, although a trend toward worse adherence was seen in subjects presenting with more than 4 risk factors (35\% in subjects with 2 to 4 RFs versus $19 \%$ in those with $>4$ RFs; $p=0.06$ ) (Figure 2).

The logistic regression model adjusted for age, gender, RFs, and health insurance system showed the following conditions as predictors of non-adherence: smoking (odds ratio $[\mathrm{OR}]=4.39, p=0.02$ ), and previous physical sedentary behavior ( $\mathrm{OR}=1.58 ; p=0.05)$ (Table 2). When SF-36 score was included in the model, SF36 < 50 score on physical health and smoking remained as the only predictors of non-adherence (OR $=11.47, p<0.0001$ and $\mathrm{OR}=4.41, p=0.02$, respectively) (Table 3 ).

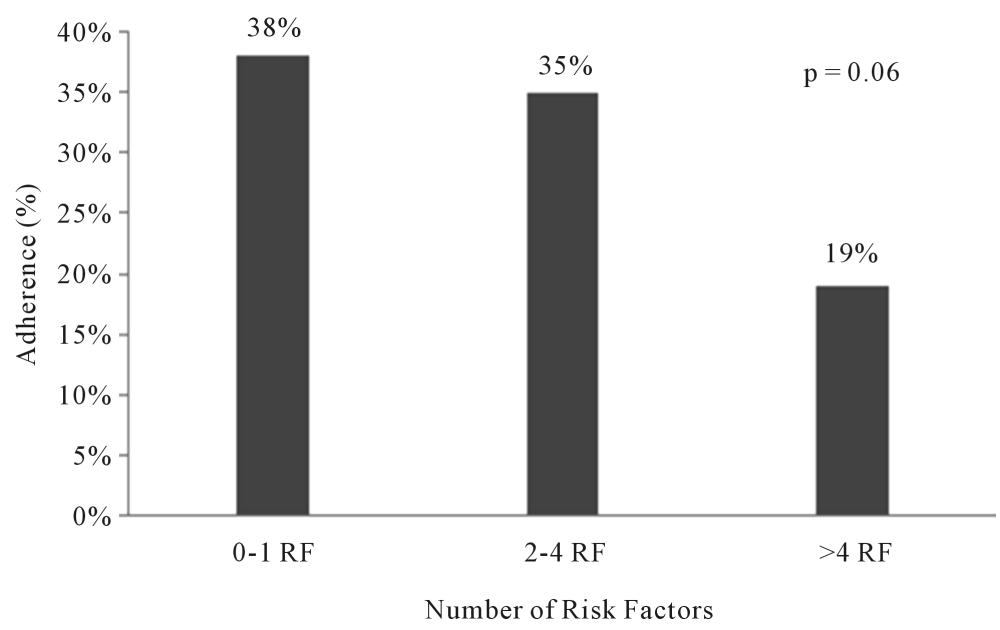

Figure 2. Adherence according to clustering of cardiovascular risk factors.

Table 2. Adjusted logistic regression model showing factors associated with adherence (adjusted for age, gender, risk factors, and health insurance).

\begin{tabular}{ccc}
\hline & Odds Ratio $(95 \% \mathrm{CI})$ & $p$-value \\
\hline Male gender & 1.00 & Reference \\
Female gender & $1.17(0.67-2.04)$ & NS \\
Age (continuous) & $1.0(0.98-1.01)$ & NS \\
Smoking (-) & 1.00 & Reference \\
Smoking (+) & $4.39(1.29-14.92)$ & 0.02 \\
Dyslipidemia $(-)$ & 1.00 & Reference \\
Dyslipidemia (+) & $0.96(0.51-1.78)$ & NS \\
Obesity (-) & 1.00 & Reference \\
Obesity (+) & $1.64(0.95-2.82)$ & 0.07 \\
Previously Active & 1.00 & Reference \\
Previously Sedentary & $1.58(1.00-2.51)$ & 0.05 \\
\hline
\end{tabular}

Odds ratio $>1$ indicates predictors of non-adherence; odds ratio $<1.00$ indicates predictors of adherence. $\mathrm{CI}$ = confidence interval; NS = not significant. 
Table 3. Fully adjusted logistic regression model showing factors associated with adherence (adjusted for age, gender, risk factors, health insurance and SF-36 score).

\begin{tabular}{ccc}
\hline & Odds Ratio $(95 \% \mathrm{CI})$ & $p$-value \\
\hline Male gender & 1.00 & Reference \\
Female gender & $0.44(0.21-0.92)$ & 0.03 \\
Age (continuous) & $0.99(0.97-1.01)$ & NS \\
Smoking $(-)$ & 1.00 & Reference \\
Smoking $\left(^{+}\right)$ & $4.41(1.25-15.62)$ & 0.02 \\
Dyslipidemia $(-)$ & 1.00 & Reference \\
Dyslipidemia (+) & $0.81(0.4-1.63)$ & NS \\
Obesity $(-)$ & 1.00 & Reference \\
Obesity (+) & $1.58(0.88-2.83)$ & NS \\
Previously Active & 1.00 & Reference \\
Previously Sedentary & $1.04(0.62-1.74)$ & NS \\
SF 36 score $>50$ both & 1.00 & Reference \\
Physical Health score $<50$ & $11.47(3.99-32.99)$ & $<0.0001$ \\
Mental Health score $<50$ & $1.61(0.82-3.19)$ & NS \\
\hline
\end{tabular}

Odds ratio $>1$ indicates predictors of non-adherence; odds ratio $<1.00$ indicates predictors of adherence. $\mathrm{CI}=$ confidence interval; NS = not significant.

\section{Discussion}

In our study adherence rates to a Phase-II-CR program were low. Patient RFs, such as score in the SF-36 < 50, active smoking, and previous physical inactivity favored non-adherence to the program rather than health systemrelated issues. On the other hand, there were no risk factors that influenced a better adherence in our population. This study emphasizes the need for prospective studies to determine all the possible factors-including patient, referring physician, health center, and health system-related factors, that may influence adherence and the success of this type of intervention.

Current guidelines assign Phase-II-CR an indication IA for use in secondary prevention [8] [20]. Phase-II-CR has been defined in the literature as the "clinical application of preventive care through a multidisciplinary professional approach to a comprehensive risk reduction and global long-term care of cardiovascular patients" [21]. Such programs include not only physical activity but also education about secondary prevention. This comprehensive concept underscores the need for the patient to adhere to the program. Since improvements in aerobic capacity, RF control, and healthy lifestyles habits are not achieved immediately, the current recommendation is that Phase-II-CR (outpatient) should last at least 36 sessions (a minimum of 3 times/week for approximately 3 months).

Our study is the first to report the adherence to a Phase-II-CR program in our country and Latin America. Overall adherence to our program was $33 \%$, which is significantly lower than the $51 \%$ reported in a recent study of 4412 participants in a group of CR centers in Wisconsin [22]. In that study, adherence was significantly better in men than women, unlike our study where there was no difference by sex. In another, smaller study from Australia $(n=284)$, Worcester and colleagues reported adherence rates of $76 \%$ in men and $79 \%$ in women [23]. The poor adherence rates observed in our patients stresses the importance of recognizing the contributing factors that are specific to our Latin population. We could speculate that the poor adherence observed in our program may have been due to the overall poor knowledge of the Chilean population about the benefits of this type of treat- 
ment. In this regard, it is important to emphasize that Phase-II-CR is not typically included in secondary prevention programs in Chile: not only are patients generally unaware of its existence and benefits but also it is not a compelling indication for physicians managing these patients. Therefore, recognizing and understanding the factors influencing adherence to these programs when these programs become more widely available in countries such as ours, in both public and private health system facilities, are essential.

Among the most important factors for non-adherence to the program, the low score in SF-36 ( $<50$ points) in physical and mental health according to international studies [19]) stood out. Our results highlight the importance of the assessment of quality of life in CR programs. Other factors that negatively influenced adherence in our group were obesity, physical inactivity and smoking. In obese subjects adherence was $25 \%$, with an OR of 1.64 as a predictor of "lower adherence". This information is extremely important given the high prevalence of overweight and obesity worldwide [17]. Recent evidence has shown that individual or group nutritional counseling within a CR program favorably affects adherence and physical activity compliance [22]. In our center, patients have free access to a nutritionist within the preventive cardiology unit. However, we did not include this variable in the analysis as all our patients are seen by the nutritionist. In view of the findings, it is an important variable that may have a positive impact on adherence and should be included in future research. With respect to obesity, it was also interesting to realize that, when adjusting for SF-36 health score in the regression model, the significance of obesity as a negative prognostic factor for adherence was lost. This finding suggests that these two variables may discriminate the same kind of subject, i.e. patients who are more resistant to lifestyle changes. Of note, morbidly obese patients in our group had a lower score on SF-36 health than non-obese patients (data not shown).

The harmful effect of smoking on adherence in both men and women, has been previously reported in the literature [14] [23] [24]. In our sample, only 7\% of the subjects were smokers. This low prevalence was anticipated as all subjects were secondary prevention patients in whom rates of smoking (especially in the first year after the cardiovascular event) are low. Phase-II-CR programs put special emphasis on smoking cessation. In general, it is important to ensure that CR programs handle smoking cessation carefully and sensitively so as not to alienate smokers who may feel marginalized or defensive about their habit. It has been reported that smokers are more likely to remain in CR programs when the difficulties of quitting are known and handled with care [25]. Ideally, both obesity and smoking should be managed with complementary therapies and multidisciplinary teams. Non-adherence rates could improve when CR programs provide comprehensive care including smoking cessation and obesity management.

Studies have shown that historical sedentary lifestyle also influences non-adherence. In women, dropout from CR programs has been strongly associated with previously complete physical inactivity [23]. These data are similar to our results in which sedentary women were less adherent to the program. Physical inactivity prior to admission to the CR program coupled with obesity and smoking, suggest that dropout from Phase-II-CR programs may be related to a reluctance to make lifestyle changes.

Our results also demonstrated that age $>65$ years old was not a factor associated with less adherence. In contrast, when subjects were stratified into age tertiles, we observed that subjects $>50$ years were more adherent than participants aged 17 to 50 years. These data differ from other studies [23] [26] showing that older adults are less adherent, likely due to factors such as difficulties in transportation, dependence on third parties to comply with the program, and other comorbidities affecting mobility [27]. Our positive findings in older patients may have been related to specific characteristics of our program, such as proximity of the center to public transportation, reminder calls to promote attendance, and individual care of the physical therapist to address joint-related pains.

Participants in our study had a high prevalence of hypertension and dyslipidemia in comparison to other studies [23] [28]. However, they did not influence adherence as it has been previously shown in one study [23]. Dyslipidemia, particularly, hypercholesterolemia and hypertension are conditions that are easily treated with diet and medication. In our program at admission and at the end of 36 sessions, all participants complete a survey that tests them on their knowledge about cardiovascular RF knowledge. In this survey, we make it clear that dyslipidemia is one of the most important RFs for atherosclerosis. All participants had well-controlled blood pressure levels and approximately $80 \%$ of them reached LDL-C $<70 \mathrm{mg} / \mathrm{dL}$. Therefore, it might be speculated that dyslipidemia and blood pressure are not barriers to compliance within our program. These results contrast with what happened in smokers and obese patients in our group- two factors that are highly dependent on patients' motivation to achieve lifestyle changes without help of medications. We did not measure adherence to lipid- 
lowering medications; however, the high proportion of patients achieving LDL-C <70 mg/dL suggests many patients were taking statins. Unlike other studies [23] [28], diabetes was not a predictive factor of non-adherence. This may have been due to the low prevalence of diabetes in our population.

Finally, we were interested on the effect of RF clustering on adherence. Patients with $>4$ RFs were less adherent to the Phase-II-CR program than those with 0 to $4 \mathrm{RF}$. With these results we might speculate that patients with $>4$ RFs could have felt that lifestyle changes were impossible to achieve and/or they could have been less aware of their illness.

Our study has several limitations. The main caveat is that this is a retrospective study and it was done in a single center and therefore, biased to sample selection. The sample size may have influenced some factors, such as the low prevalence of diabetes. Moreover, in the statistical analysis only the factors which were anticipated by the literature as predictors of adherence were included in the database.

\section{Conclusion}

Future studies with larger number of subjects or multicenter studies could identify other predisposing factors to non-adherence. Until then, it is important to raise awareness about the benefits of Phase-II-CR programs, patient expectations, and possible barriers to successful implementation and participation in structured CR programs in order to improve adherence rates.

\section{Disclosures}

The authors declare that there is no conflict of interest regarding the publication of this paper. All authors have read and approved the manuscript.

\section{References}

[1] INE (2010) Estadísticas Vitales: Informe Anual 2008. http://www.ine.cl/canales/menu/publicaciones/calendario_de_publicaciones/pdf/21_12_10/vit_08211210.pdf

[2] Nazzal, C. and Alonso F.T. (2011) Incidencia y letalidad por infarto agudo del miocardio en Chile: 2001-2007. Revista médica de Chile, 139, 1253-1260. http://dx.doi.org/10.4067/S0034-98872011001000002

[3] Lawler, P.R., Filion, K.B. and Eisenberg, M.J. (2011) Efficacy of Exercise-Based Cardiac Rehabilitation Post-Myocardial Infarction: A Systematic Review and Meta-Analysis of Randomized Controlled Trials. American Heart Journal, 162, 571.e2-584.e2. http://dx.doi.org/10.1016/j.ahj.2011.07.017

[4] Smith S.C., Benjamin E.J., Bonow R.O., Braun L.T., Creager M.A., Franklin B.A., et al. (2011) AHA/ACCF Secondary Prevention and Risk Reduction Therapy for Patients with Coronary and Other Atherosclerotic Vascular Disease: 2011 Update: A Guideline from the American Heart Association and American College of Cardiology Foundation endorsed by the World Heart Federation and the Preventive Cardiovascular Nurses Association. Circulation, 124, 24582473. http://dx.doi.org/10.1161/CIR.0b013e318235eb4d

[5] Hsu, C.J., Chen, S.Y., Su, S., Yang, M.C., Lan, C., Chou, N.K., et al. (2011) The Effect of Early Cardiac Rehabilitation on Health-Related Quality of Life among Heart Transplant Recipients and Patients with Coronary Artery Bypass Graft Surgery. Transplantation Proceedings, 43, 2714-2717. http://dx.doi.org/10.1016/j.transproceed.2011.04.025

[6] Acevedo, M., Krämer, V., Bustamante, M.J., Yañez, F., Guidi, D., Corbalán, R., et al. (2013) Rehabilitación cardiovascular y ejercicio en prevención secundaria. Revista médica de Chile, 141, 1305-1312. http://dx.doi.org/10.4067/s0034-98872013001000010

[7] Hammill, B.G., Curtis, L.H., Schulman, K.A. and Whellan, D.J. (2010) Relationship between Cardiac Rehabilitation and Long-Term Risks of Death and Myocardial Infarction among Elderly Medicare Beneficiaries. Circulation, 121, 63-70. http://dx.doi.org/10.1161/CIRCULATIONAHA.109.876383

[8] Suaya, J.A., Shepard, D.S., Normand, S.L., Ades, P.A., Prottas, J. and Stason, W.B. ( 2007) Use of Cardiac Rehabilitation by Medicare Beneficiaries after Myocardial Infarction or Coronary Bypass Surgery. Circulation, 116, 1653-1662. http://dx.doi.org/10.1161/CIRCULATIONAHA.107.701466

[9] Leon, A.S., Chair, M.S. Franklin, B.A., Costa, F., Balady, G.J., Berra, K.A., et al. (2005) An American Heart Association scientific statement from the Council on Clinical Cardiology (Subcommittee on Exercise, Cardiac Rehabilitation, and Prevention); Council on Nutrition, Physical Activity, and Metabolism (Subcommittee on Physical Activity) in collaboration with the American Association of Cardiovascular and Pulmonary Rehabilitation. Cardiac Rehabilitation and Secondary Prevention of Coronary Heart Disease. Circulation, 111, 369-376. http://dx.doi.org/10.1161/01.CIR.0000151788.08740.5C 
[10] Yohannes, A.M., Yalfani, A., Doherty, P. and Bundy, C. (2007) Predictors of Drop-Out from an Outpatient Cardiac Rehabilitation Programme. Clinical Rehabilitation, 21, 222-229. http://dx.doi.org/10.1177/0269215506070771

[11] Santibáñez, C., Pérez-Terzic, C., López-Jiménez, F., Cortés-Bergoderi, M., Araya M.V. and Burdiat, G. (2012) Situación actual de la rehabilitación cardiaca en Chile. Revista médica de Chile, 140, 561-568. http://dx.doi.org/10.4067/S0034-98872012000500002

[12] Scott, L.A., Ben-Or, K. and Allen J.K. (2002) Why Are Women Missing from Outpatient Cardiac Rehabilitation Programs? A Review of Multilevel Factors Affecting Referral, Enrollment, and Completion. Journal of Women's Health, 11, 773-791. http://dx.doi.org/10.1089/15409990260430927

[13] Todaro, J.F., Shen, B.J., Niaura, R., Tilkemeier, P.L. and Roberts, B.H. (2005) Do Men and Women Achieve Similar Benefits from Cardiac Rehabilitation? Journal of Cardiopulmonary Rehabilitation, 24, 45-51.

[14] Jackson, L., Leclerc, J., Erskine, Y. and Linden, W. (2005) Getting the Most Out of Cardiac Rehabilitation: A Review of Referral and Adherence Predictors. Heart, 91, 10-14. http://dx.doi.org/10.1136/hrt.2004.045559

[15] Grundy, S.M., Brewer Jr., H.B., Cleeman, J.I., Smith Jr., S.C. and Lenfant, C. (2004) Definition of Metabolic Syndrome: Report of the National Heart, Lung, and Blood Institute/American Heart Association Conference on Scientific Issues Related to Definition. Circulation, 109, 433-438. http://dx.doi.org/10.1161/01.CIR.0000111245.75752.C6

[16] Alberti, K.G.M.M., Eckel, R.H., Grundy, S.M., Zimmet, P.Z., Cleeman, J.I., Donato, K.A., et al. (2009) Harmonizing the Metabolic Syndrome: A Joint Interim Statement of the International Diabetes Federation Task Force on Epidemiology and Prevention; National Heart, Lung, and Blood Institute; American Heart Association; World Heart Federation; International Atherosclerosis Society; and International Association for the Study of Obesity. Circulation, 120, 16401645. http://dx.doi.org/10.1161/CIRCULATIONAHA.109.192644

[17] Ministerio de Salud, Pontificia Universidad Católica y Universidad Alberto Hurtado (2011) Encuesta Nacional de Salud. Chile 2009-2010. http://www.redsalud.gov.cl/portal/url/item/99c12b89738d80d5e04001011e0113f8.pdf

[18] Krämer, V., Acevedo, M., Orellana, L., Chamorro, G., Corbalán, R., Bustamante, M.J., et al. (2009) Actividad física y potencia aeróbica: Cómo influyen sobre los factores de riesgo cardiovascular clásicos y emergentes? Revista Médica de Chile, 137, 737-745. http://dx.doi.org/10.4067/S0034-98872009000600002

[19] (1998) U.S. Population Norms. United States of America. http://www.sf-36.org/research/sf98norms.pdf

[20] Perk, J., De Backer, G., Gohlke, H., Graham, I., Reiner, Z., Verschuren, M., et al. (2012) European Guidelines on Cardiovascular Disease Prevention in Clinical Practice (Version 2012). The Fifth Joint Task Force of the European Society of Cardiology and Other Societies on Cardiovascular Disease Prevention in Clinical Practice (Constituted by Representatives of Nine Societies and by Invited Experts). European Heart Journal, 33, 1635-1701. http://dx.doi.org/10.1093/eurheartj/ehs092

[21] Corrá, U., Piepoli, M.F., Carré, F., Heuschmann, P., Hoffmann, U., Verschuren, M., et al. (2010) Secondary Prevention through Cardiac Rehabilitation: Physical Activity Counseling and Exercise Training: Key Components of the Position Paper from the Cardiac Rehabilitation Section of the European Association of Cardiovascular Prevention and Rehabilitation. European Heart Journal, 31, 1967-1974. http://dx.doi.org/10.1093/eurheartj/ehq236

[22] Turk-Adawi, K.I., Oldridge, N.B., Tarima, S.S., Stason, W.B. and Shepard, D.S. (2013) Cardiac Rehabilitation Patient and Organizational Factors: What Keeps Patients in Programs? Journal of the American Heart Association, 2, e000418. http://dx.doi.org/10.1161/JAHA.113.000418

[23] Worcester, M.U., Murphy, B.M., Mee, V.K., Roberts, S.B. and Goble, A.J. (2004) Cardiac Rehabilitation Programmes: Predictors of Non-Attendance and Drop-Out. European Journal of Cardiovascular Prevention and Rehabilitation, 11, 328-335. http://dx.doi.org/10.1097/01.hjr.0000137083.20844.54

[24] Oldridge, N.B. and Streiner, D.L. (1990) The Health Belief Model: Predicting Compliance and Dropout in Cardiac Rehabilitation. Medicine \& Science in Sports \& Exercise, 22, 678-683. http://dx.doi.org/10.1249/00005768-199010000-00020

[25] Wakefield, M., Roberts, L. and Rosenfeld, E. (1997) Smoking Cessation among People with Diabetes: Beliefs and Barriers. Health Promotion Journal of Australia, 7, 46-51.

[26] McGee, H.M. and Horgan, J.H. (1992) Cardiac Rehabilitation Programmes: Are Women Less Likely to Attend? British Medical Journal, 305, 283-284. http://dx.doi.org/10.1136/bmj.305.6848.283-a

[27] Jones, M., Jolly, K., Raftery, J., Lip, G.Y., Greenfield, S. and BRUM Steering Committee (2007) "DNA” May Not Mean "Did Not Participate": A Qualitative Study of Reasons for Non-Adherence at Home- and Centre-Based Cardiac Rehabilitation. Family Practice, 24, 343-357. http://dx.doi.org/10.1093/fampra/cmm021

[28] Dunlay, S.M., Witt, B.J., Allison, T.G., Hayes, S.N., Weston, S.A., Koepsell, E., et al. (2009) Barriers to Participation in Cardiac Rehabilitation. American Heart Journal, 158, 852-859. http://dx.doi.org/10.1016/j.ahj.2009.08.010 